\section{LEGIONELLA RISK ASSESSMENTS DUE}

HTM 01-04 and 01-05 state that all registered dental practices need to have undertaken a Legionella risk assessment and written scheme by this month (April 2011). Specialist Legionella consultancy Building Monitoring Services (BMS) can help you comply with this requirement.

A Legionella risk assessment assesses the water systems within a property with regard to its ability to increase and spread Legionella bacteria which could infect patients and employees. A written scheme details what needs to be done to control the Legionella risk.

BMS are members of the Legionella Control Association, recommended by the HTM, and have created a bespoke,

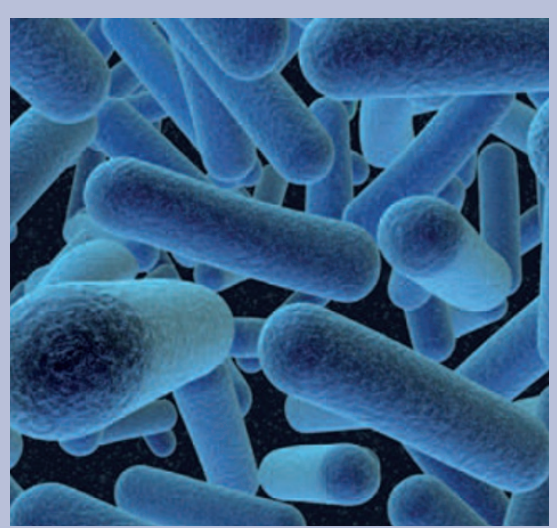

affordable service specifically designed for dental practices.

The specialist service includes a Legionella risk assessment for all water systems present; schematic drawings of systems; and a detailed report of any remedial work required and possible monitoring.

Reader response number 57

\section{CREATE SATISFYING RESTORATIONS}

GC has announced a new series of courses for 2011 that will take place at the GC Campus meeting and education centre based at the European headquarters in Leuven, Belgium.

GC has recently launched an improved composite system with G-aenial. The hands-on training courses have been designed for dentists to learn how to place the very best composite using a combination of materials. After analysing the structure of the surrounding

\section{WORLD FIRST DUE TO LAUNCH IN MANCHESTER}

A world innovation in oral health will be launched by Philips at this year's British Dental Conference and Exhibition in Manchester in May. The new product is a world first, possibly on the scale of the introduction of sonic technology for tooth cleaning - but is not a toothbrush.

The new product comes from Philips' immediate field of competence in oral healthcare and biofilm management of plaque. Philips will also be announcing teeth, simple steps are used to create the perfect restoration using G-aenial. Even monochromatic restorations look great due to the unique chameleon effect of the composite. Together with materials from the Gradia Lab kit that can be used in the mouth, you will learn how to create the most satisfying restorations for you and your patients.

For more advanced users there is an additional course that adopts a theoretical and practical approach to this sophisticated direct composite system.

Reader response number 58

ground-breaking developments to the Sonicare sonic toothbrush range which will take brushing upscale to a more sophisticated level.

As well as launching two new Sonicare products at the event, Philips will also be presenting the full suite of current Sonicare toothbrushes including the Flexcare+ with its five brushing modes, the HealthyWhite for those motivated by whiter teeth, the HydroClean for an introduction to sonic cleaning, and the Sonicare For Kids brush.

Philips will be located on stand C16. Reader response number 59
FINANCIAL ADVICE TAILORED TO YOU

money4dentists will be on hand to provide you with financial advice and the latest legal information at the British Dental Conference and Exhibition in Manchester in May.

money4dentists is dedicated to identifying priorities, setting goals and suggesting methods of achieving these. Enlisting the use of the most advanced software programs and modern-day communication methods, and with over half a century of experience, money4dentists not only offers confidential, independent financial advice, but it can also provide an efficient service, tailored to the needs of the individual practitioner.

Reader response number 60

\section{FUTURE-PROOF YOUR BUSINESS}

Kevin Coyle and his experienced team from The Dental Plan, many of whom are successful dentists in their own right, will be on hand at this year's British Dental Conference and Exhibition in Manchester in May to provide practice principals with advice on how to financially 'future-proof' their businesses.

Visit The Dental Plan stand to find out more about their flexible and rewarding patient payment plans, which offer a regular monthly income and guaranteed twice-yearly cash rebates, amongst other perks, including a stake in the company upon joining.

In addition, The Dental Plan's expert advisers can also explain how they can help you market your practice more effectively, implement customer loyalty programmes, as well as help you prepare for new regulations such as CQC, thanks to their comprehensive quality management systems and staff training programmes.

If you are thinking of switching from an NHS to a private practice, or just need some help restructuring your business, talk to a member of The Dental Plan team, who will be only too glad to help.

Reader response number 61 